\title{
ÍNDICE DE PROTEÇÃO E DEFESA CIVIL: NECESSIDADE E VIABILIDADE
}

\begin{abstract}
Euler L. T. Lima ${ }^{1}$
Airton Bodstein ${ }^{2}$

\section{RESUMO}

A Redução de Riscos de Desastres (RRD) traz em si uma gama de fatores que guardam entre suas relações uma grande complexidade. Dentro da Política Nacional de Proteção e Defesa Civil, definida pela Lei 12.608 de 10 de abril de 2012, os municípios carregam a responsabilidade direta pela execução da maior parte das ações preconizadas. Neste contexto, ao buscar-se uma forma de mensurar a adequação das ações realizadas às demandas apresentadas, percebe-se que não existe uma metodologia minimamente estabelecida para fazê-lo. Neste estudo percorreu-se o desenvolvimento das ações de Proteção e Defesa Civil desde as desenvolvidas internacionalmente, quanto nos diversos níveis federativos do Brasil. Neste caminho observou-se que existe a necessidade de que haja uma forma de mensurar essas ações e propõe-se que se comece pelo ente municipal. De forma que se possa buscar um desempenho adequado às necessidades existentes no município. Por isso é fundamental a criação de um Índice de Proteção e Defesa Civil que deverá ser composto por indicadores que possam medir esse universo dentro de suas próprias peculiaridades e complexidades.
\end{abstract}

Palavras-chave: Defesa Civil; Índice de Desenvolvimento; Gestão de Riscos; Município.

\footnotetext{
${ }^{1}$ Mestrando em Defesa e Segurança Civil pela Universidade Federal Fluminense (Niterói, RJ).

${ }^{2}$ Coordenador do Programa de Mestrado em Defesa e Segurança Civil da Universidade Federal Fluminense (Niterói, RJ).
} 


\title{
CIVIL DEFENSE AND PROTECTION INDEX: NEED AND FEASIBILITY
}

\begin{abstract}
Disaster Risk Reduction (DRR) brings with it a range of factors that have a great complexity among their relationships. Within the National Policy for Civil Defense and Protection, defined by Law 12,608 of April 10, 2012, municipalities bear direct responsibility for carrying out most of the recommended actions. In this context, when looking for a way to measure the adequacy of actions taken to the demands presented, it is clear that there is no minimally established methodology to do so. This study covered the development of Civil Defense and Protection actions from those developed internationally, as well as at the various federal levels in Brazil. In this way, it was observed that there is a need for a way to measure these actions and it is proposed to start with the municipal entity. So that it is possible to seek an adequate performance to the existing needs of the municipality. Therefore, it is essential to create a Civil Defense and Protection Index, which should be composed of indicators that can measure this universe within its own peculiarities and complexities.
\end{abstract}

Keywords: Civil Defense; Development Index; Risk Management; City. 


\section{INTRODUÇÃO}

Proteção e Defesa Civil é uma área que traz em si uma grande complexidade, abarcando uma série de fatores que interagem de diversas maneiras para que o sistema como um todo possa conseguir atender às demandas que Ihe são impostas. Dessa maneira, faz-se muito importante um detalhamento das ações para RRD, algo que permita uma análise setorizada e individualizada de suas diversas facetas, ao mesmo tempo que possa ser posta de forma sistêmica e integrada. Um passo importante neste sentido, em um passado mais recente, foi a criação da Lei 12.608 de 10 de abril de 2012 que institui a Política Nacional de Proteção e Defesa Civil - PNPDEC; dispõe sobre o Sistema Nacional de Proteção e Defesa Civil - SINPDEC e o Conselho Nacional de Proteção e Defesa Civil - CONPDEC; autoriza a criação de sistema de informações e monitoramento de desastres. Esta lei traz as atribuições e competências de cada um dos entes federados, além das ações comuns a todos eles, de forma a possibilitar não só as obrigações de cada um, mas também de permitir uma melhor visualização do sistema como um todo.

Sabemos, porém, que existem muitos passos a serem dados para 0 avanço em uma determinada área e que a regulamentação, ou o estabelecimento claro de regras, apresenta-se apenas como um deles, já que é imprescindível uma boa composição dos recursos humanos, a aquisição de recursos materiais adequados para que as atividades sejam desempenhadas 0 mais próximo possível do ideal e, no caso dos municípios, sendo a DCM um órgão público, a própria vontade política fundamental e, na maioria dos casos, o fator preponderante para o seu sucesso.

Nos deparamos atualmente com uma grande dificuldade em avaliar a melhor estruturação destes órgãos já que a lei 12.608 e as demais diretrizes a respeito do tema estabelecem as ações a serem realizadas, mas a forma como devem ser fica a cargo do ente responsável e, neste aspecto, faltam parâmetros para que tais ações sejam avaliadas, trazendo, por um lado, 
prejuízo aqueles gestores que desejam de fato fazer um bom trabalho na redução de riscos de desastres e, por outro lado, uma condição favorável aos outros que porventura, queiram fazer um uso predominantemente político desta estrutura.

Daí decorre a necessidade identificada em fazer o estabelecimento destes parâmetros, buscar respostas e soluções de base técnica para a disponibilização dos meios necessários para o bom desenvolvimento do Órgão Municipal de Proteção e Defesa Civil para que desta maneira possa haver uma maior objetividade e transparência nas escolhas que forem feitas no sentido de ampliações, aquisições e investimentos públicos na atividade, servindo ainda de estímulo para o desenvolvimento da mesma.

\section{METODOLOGIA}

Podemos caracterizar a pesquisa como uma atividade para a investigação de problemas teóricos ou práticos por meio de emprego de processos científicos (CERVO, 2007).

Desta forma, buscou-se neste trabalho uma pesquisa bibliográfica e documental que pudesse embasar as observações realizadas e as conclusões apresentadas de acordo com a realidade vivenciada no tocante à proteção de defesa civil no Brasil, em especial no Estado do Rio de Janeiro que é o foco da análise.

A metodologia utilizada no presente trabalho se constitui em uma pesquisa exploratória, já que têm como objetivo proporcionar maior familiaridade com o problema, com vistas a torná-lo mais explícito ou a construir hipóteses, e ampliar o conhecimento sobre a gestão da proteção e defesa civil nos diversos níveis, ainda conforme Gil (2002), podemos dizer que estas pesquisas têm como objetivo principal o aprimoramento de ideias ou a descoberta de intuições.

É também uma pesquisa descritiva, pois tem como objetivo primordial a descrição das características de determinada população ou fenômeno, neste 
caso o cenário de complexidade que envolve os entes federativos na temática estudada.

Em relação aos procedimentos técnicos, foi utilizada tanto a pesquisa bibliográfica, quanto a documental. Aquela é desenvolvida com base em material já elaborado, constituído principalmente de livros e artigos científicos. Esta se assemelha muito à pesquisa bibliográfica, a diferença essencial entre as duas está na natureza das fontes. Enquanto a pesquisa bibliográfica se utiliza fundamentalmente das contribuições dos diversos autores sobre determinado assunto, a pesquisa documental vale-se de materiais que não recebem ainda um tratamento analítico, ou que ainda podem ser reelaborados de acordo com os objetos da pesquisa. (GIL, 2002)

Desta maneira, buscou-se realizar levantamento histórico das ações anteriormente desenvolvidas pelo sistema de defesa civil como um todo, até as atuais atribuições instituídas pela Lei Federal ํo 12.608/2012, fontes oficiais de informação, legislações, publicações, sítios, Constituição da República Federativa do Brasil de 1988, leis e decretos federais, Instruções Normativas, Resoluções e todo tipo de documento que pudesse caracterizar as condições atuais de gestão da proteção e defesa civil, além do nível mundial, nos diversos entes federativos do Brasil, para que pudéssemos perceber a complexidade que envolve esta temática e a necessidade da criação de ferramentas que possam contribuir para o aumento da eficiência no emprego dos meios e recursos disponíveis para este fim.

\section{A GESTÃO DE DESASTRES}

O homem sempre conviveu com adversidades e, por vezes, foi submetido a situações catastróficas durante sua existência. Secas, queimadas e diversas outras situações, que colocaram a própria existência da humanidade em risco, precisaram ser superadas para chegarmos ao estágio evolutivo em que estamos. 
Já no período contemporâneo, observou-se a estruturação das atividades de proteção e defesa civil, com um foco voltado para as demandas associadas aos efeitos da guerra. Essa realidade começou a apresentar mudanças a partir da década de 1940, quando essa ideia foi mudando e a gestão de risco passou a ter uma perspectiva bem mais ampla, envolvendo as próprias instituições de proteção e defesa civil, a gestão pública e a sociedade como um todo.

\subsection{CONTEXTO INTERNACIONAL}

Algo que merece destaque neste sentido foi "a Assembleia Geral das Nações Unidas [que] estabeleceu, já em 1987, um importante marco no histórico da gestão de risco internacional, ao definir a Década Internacional para a Redução dos Desastres Naturais (DIRDN) para o período de 1990 a 1999 (DPP-SEDEC, 2017, p.31). Esta iniciativa fez com que os estados membros assumissem um compromisso no sentido de desenvolver uma cooperação internacional em relação à redução dos riscos de desastres. A seguir, abordaremos alguns destes projetos.

\subsubsection{Marco de Sendai}

A primeira Conferência Mundial sobre a redução de riscos de desastres naturais promovida pela ONU aconteceu em maio de 1994, na cidade japonesa de Yokohama. Já no ano de 1997 foi criado o Projeto Esfera, que tinha o objetivo de elaborar normas mínimas, mas que fossem universais, para as ações de resposta humanitária. Essas normas são focadas em cinco setores considerados fundamentais, a saber: abastecimento de água e saneamento; nutrição; ajuda alimentar; abrigo; e planejamento de locais e cuidados médicos.

Em 2005 foi realizada, na cidade de Kobe, a II Conferência Mundial sobre a Redução do Risco de Desastres, onde foi estabelecido o Marco de Ação de Hyogo 2005-2015, que se alinhava aos Objetivos de Desenvolvimento do Milênio, documento este que foi sucedido pelo atual Marco de Ação de 
Sendai, aprovado pelos Estados-Membros, no ano de 2015, na III Conferência Mundial das Nações Unidas sobre a Redução do Risco de Desastres.

O Marco de Ação de Sendai tem como objetivo:

Prevenir novos riscos e reduzir o risco de desastres existente, implementando medidas econômicas, estruturais, jurídicas, sociais, de saúde, culturais, educacionais, ambientais, tecnológicas, políticas e institucionais integradas e inclusivas que previnam e reduzam a exposição a perigos e a vulnerabilidade a desastres, aumentar a preparação para resposta e recuperação, e, assim, aumentar a resiliência (BRASIL, 2019).

A partir deste documento e com foco maior na prevenção do risco, estabeleceram-se diretrizes principais, foram propostas sete metas, estabeleceu-se uma articulação clara entre as ações no âmbito nacional, local, regional e global. Além disso, foram definidas as responsabilidades de todas as partes interessadas. Este marco estabeleceu quatro prioridades:

1. Compreensão do risco de desastres;

2. Fortalecimento da governança para gerenciar o risco de desastres;

3. Investimento na redução do risco de desastres para a resiliência;

4. Melhoria na preparação para desastres com foco em resposta efetiva e na máxima "Reconstruir Melhor que Antes" aplicável às ações de recuperação, reabilitação e reconstrução.

\subsubsection{Campanha Construindo Cidades Resilientes}

A Campanha Construindo Cidades Resilientes tem seu escopo na resiliência a desastres, ou seja, na capacidade de uma cidade para planejar, mitigar, responder, recuperar-se, adaptar-se e crescer após grandes desastres, tendo em conta suas circunstâncias físicas, econômicas, ambientais e sociais particulares. 
O projeto foi lançado internacionalmente, em 2010, pelo Escritório das Nações Unidas para a Redução do Risco de Desastres - UNISDR, embasando os 10 passos essenciais para fins de incremento da resiliência a desastres em nível local. No ano de 2015, por ocasião do Marco de Sendai, houve uma reformulação da campanha para a adequação às novas diretrizes estabelecidas (DPP-SEDEC, 2017, p.36).

Os municípios que desejem fazer a adesão à Campanha Construindo Cidades Resilientes devem adotar os 10 passos essenciais instituídos pelo projeto, que são divididos em aspectos básicos, aspectos operativos e aspectos para uma melhor reconstrução.

No Brasil, segundo o Ministério do Desenvolvimento Regional, a adesão à campanha traz uma nova abordagem à questão e produz uma reestruturação na Secretaria Nacional de Proteção e Defesa Civil, promovendo integração federativa relacionada às ações a serem desenvolvidas. Vale o destaque de que o Brasil é o país com o maior número de municípios inscritos no mundo, o que se reflete em um aspecto bastante positivo, pois, embora a inscrição por si só não transforme o município em uma cidade resiliente, porque o ente municipal precisa desenvolver as ações propostas, demonstra um aumento de conscientização relacionado aos riscos de desastres por parte dos gestores locais.

\subsubsection{Acordo de Paris}

Durante a 21a Conferência das Partes (COP21) da United Nations Framework on Climate Change (UNFCCC), foi adotado um acordo que visa fortalecer a resposta global às questões ligadas às mudanças climáticas no planeta, buscando reforçar a capacidade dos países em lidar com o problema. O acordo de Paris foi aprovado pelos 195 países para reduzir a emissão de gases do efeito estufa dentro da ideia do desenvolvimento sustentável, com o compromisso de manter o aumento da temperatura média global em bem menos de $2^{\circ} \mathrm{C}$ acima dos níveis pré-industriais e de envidar esforços para 
limitar o aumento da temperatura a $1,5^{\circ} \mathrm{C}$ acima dos níveis pré-industriais (BRASIL, 2016).

Esta iniciativa é defendida tendo em vista as consequências desastrosas que podem vir a ocorrer, no caso de não haver uma redução nas emissões desses gases e, por conseguinte, de não se buscar atender aos limites previstos, pois:

Com menos de $1{ }^{\circ} \mathrm{C}$ de aquecimento já temos, toda semana, uma má notícia em algum lugar do mundo, inclusive no Brasil, de acidentes ligados a climas mais extremos, chuvas fortes, secas que se intensificam, tornados, deslizamentos de terra. Isso vem acontecendo com frequência e intensidade maior nos últimos anos e tende a se agravar (EBC, 2015).

Segundo o Ministério do Meio Ambiente, para que se consiga alcançar o objetivo final do acordo é necessário que os governos busquem a construção de seus próprios compromissos, que são denominadas Pretendidas Contribuições Nacionalmente Determinadas (ilDC, na sigla em inglês). No projeto, é previsto ainda o financiamento climático onde os países desenvolvidos são obrigados a investir 100 bilhões de dólares por ano, nos países em desenvolvimento, em medidas contra as mudanças climáticas.

\subsubsection{Nova Agenda Urbana}

No ano de 2016, ocorreu a Terceira Conferência das Nações Unidas sobre Moradia e Desenvolvimento Urbano Sustentável, na cidade de Quito, no Equador. Na ocasião foi consolidado o documento que irá nortear a urbanização sustentável pelos próximos 20 anos, chamado Nova Agenda Urbana.

Dentre as premissas do documento, estão "a igualdade de oportunidades para todos; o fim da discriminação; a importância das cidades mais limpas; a redução das emissões de carbono; o respeito pleno aos direitos 
dos refugiados e migrantes; a implementação de melhores iniciativas verdes e de conectividade, entre outras" (DPP-SEDEC, 2016).

A Nova Agenda Urbana, segundo a ONU, tem o foco em uma visão compartilhada de desenvolvimento urbano que venha a oferecer oportunidades de forma igualitária, acesso aos benefícios e oportunidades que a cidade possa oferecer, além de combate à discriminação e, no caso mais específico de redução de riscos de desastres, uma urbanização sustentável e equilibrada, de maneira a tornar a cidade mais resiliente (ONU, 2016).

\subsection{CONTEXTO DA AMÉRICA LATINA}

Vistas as iniciativas de caráter global em relação à redução do risco de desastres, vale uma explanação referente aos principais projetos desta natureza no contexto da América Latina, que compartilha de semelhanças regionais e espaços comuns de cooperação.

\subsubsection{União das Nações Sul-Americanas (UNASUL) e Progresso da América do Sul (PROSUL)}

No ano de 2013, foi criado o Grupo de Alto Nível Sobre Gestão de Riscos de Desastres, formado por representantes de Argentina, Bolívia, Brasil, Chile, Colômbia, Equador, Guiana, Paraguai, Peru, Suriname, Uruguai e Venezuela. A criação se deu durante a Reunião Ordinária do Conselho de Ministros de Relações Exteriores da UNASUL.

Os objetivos do projeto envolviam, dentre outras coisas, definir, a partir de avaliações nacionais e de aportes dos Conselhos Ministeriais da UNASUL, as capacidades, riscos e desafios comuns dos estados membros em matéria de gestão de risco de desastres; desenvolver um glossário de termos que expresse uma visão compartilhada; contribuir para a adoção de políticas, estratégias e ferramentas compartilhadas em matéria de redução do risco de desastres; e promover a cooperação sobre o tema por meio de programas, projetos e outras ações de cooperação sul - sul e triangular, neste caso 
envolvendo nações fora da região, de acordo com as normativas da UNASUR (DPP-SEDEC, 2017, p.37).

Embora tenha havido proposições objetivas e de grande potencial para as questões relativas à proteção e defesa civil, este projeto, segundo o Governo Federal Brasileiro, vem atravessando um grande período de crise, de forma que um grupo de países - Brasil, Argentina, Chile, Colômbia Paraguai e Peru suspenderam sua participação na UNASUL para integrar o Fórum para o Progresso da América Latina (PROSUL), que foi idealizado pelo presidente chileno Sebastian Piñera. As bases deste projeto estão em fase de elaboração (EBC, 2019).

\subsubsection{Plataforma Regional para a Redução de Risco de Desastres}

O tema "redução de riscos de desastres" é amplo e complexo, envolvendo vários campos da ciência para a devida compreensão de suas questões, demandando para seu desenvolvimento um estudo aprofundado de suas diversas nuances, além da necessidade da interação e troca de conhecimentos entre diversos saberes, sendo o debate um fator fundamental neste processo.

Neste sentido, projetos e iniciativas que visem oferecer espaço para a troca de experiências ligadas a esta área são ações de suma importância. É dentro deste conceito que foi criada a Plataforma Regional para Redução do Risco de Desastres das Américas - PRRRD América - que é um fórum multisetorial, onde são definidas as tendências e áreas prioritárias de avanço e fortalecimento, de ampla participação, que reflete os compromissos e as preocupações dos governos (nacionais, subnacionais e locais), das organizações intergovernamentais, das organizações internacionais, das organizações não governamentais, das organizações comunitárias, das instituições científicas e acadêmicas, do setor privado e dos meios de comunicação (DPP-SEDEC, 2017, p.38). 
O PRRRD das Américas pode ser traduzido como um encontro que oferece esta oportunidade de intercâmbio de informações, proporcionando a possibilidade de compartilhamento de processos adotados em diferentes locais que possam ser traduzidos em boas práticas, especialmente no tocante à implementação das ações preconizadas pelo Marco de Sendai.

\subsubsection{Rede de Estudos Sociais em Prevenção de Desastres na América Latina - LA RED}

Para que se possa fazer uma boa gestão de risco é fundamental que haja pesquisa e produção de conhecimento na área, fundamentada na visão técnico-científica, de maneira a oferecer uma base lógica para a tomada de decisão. Foi com este intuito que um grupo multidisciplinar de 16 especialistas em desastres de diferentes instituições governamentais, não governamentais, acadêmicas e internacionais de sete países (Brasil, Canadá, Colômbia, Costa Rica, Equador, México e Peru) criou a Rede de Estudos Sociais em Prevenção de Desastres na América Latina - LA RED (CEPED/ UFSC, 2014, p.46).

Esta organização foi criada em 1992, em Puerto Limón, Costa Rica, e o foco inicial era funcionar como um mecanismo para facilitar a investigação comparativa sobre os desastres desde uma perspectiva social. Atualmente a LA RED transformou-se no espaço de encontro de diferentes países da América Latina e do Caribe, além de outros (CEPED/ UFSC, 2014, p.46).

A LA RED foi criada como uma alternativa, aberta e independente para o desenvolvimento da gestão de riscos de desastres, sendo atualmente uma referência indispensável para a pesquisa, as informações, a capacitação, a educação e a formulação de iniciativas de política relacionada com a temática de desastres (CEPED/ UFSC, 2014, p.46).

A Rede de Estudos Sociais em Prevenção de Desastres na América Latina promoveu sua primeira reunião geral no ano de 1992, onde foram formuladas cinco áreas de intervenção para sua Agenda de Investigação e Constituição Orgânica (DPP-SEDEC, 2017, p.39): 
i. Estado, sistemas políticos e prevenção de desastres;

ii. Desastres e modelo de desenvolvimento;

iii. Desastres e cultura;

iv. Modelos organizativos-administrativos para a prevenção de desastres;

v. Sistemas de instrumentos para a prevenção, atenção e recuperação a desastres.

\subsection{A PROTEÇÃO E DEFESA CIVIL NO BRASIL}

O Brasil é um país que não possui, mesmo atualmente, uma sólida cultura voltada à redução de risco de desastres. Segundo (BARRERA; SOUZA; MARTINS, 2018, P. 2) "O paraíso tropical brasileiro, rico e abundante em riquezas naturais, sempre gerou uma mentalidade de que o país não apresenta riscos de desastres tais quais em outros países do mundo".

Além dessa questão de uma falsa sensação de que o país não está sujeito aos desastres, temos dificuldades em atuar de maneira preventiva, de maneira que esses eventos "sempre possuíram características socioculturais em seus efeitos nefastos e sempre foram produzidas leis de vieses responsivos às ocorrências adversas" (SOUZA, 2019, p. 27).

$\mathrm{Na}$ história do Brasil, Barreira; Souza e Martins (2018) destacam que a primeira legislação que se preocupou com o direito coletivo em calamidades públicas foi a carta magna de 1891. Em seguida, as novas constituições oscilaram entre dar mais ou menos atenção à temática de desastres, até que a promulgada em 1967 traz destaque à defesa contra calamidades públicas, especialmente à questão das inundações, possivelmente influenciada pelas chuvas de 1966 no estado do Rio de Janeiro que deixaram quase 1000 mortos.

Corroborando com essa ideia, conforme nos indica Santos (2018, p.3), pode-se dizer que a Defesa Civil teve seu surgimento, ao menos da maneira como a conhecemos hoje, em meio à Segunda Guerra Mundial, quando em 
função dos pesados ataques sofridos, principalmente em função do uso de aeronaves de combate, houve grande destruição e prejuízo de diversas naturezas, o que trouxe a necessidade de uma resposta adequada e organizada.

A "Constituição Cidadã" de 1988 pode ser considerada um marco na temática de Proteção e Defesa Civil, já que trouxe a definição das competências entre os entes federativos, lançando as bases para o modelo que encontramos atualmente no país, onde podemos destacar:

A União também é responsável pelo planejamento e promoção da defesa das calamidades públicas, especialmente secas e inundações (art. 21,XVIII). Aos três níveis da federação compete: promover programas de construção de moradias e melhoria das condições habitacionais e de saneamento básico (artigos 21,XX e 23,IX); legislar, proteger e preservas o meio ambiente (artigos 23, VI e VII e $24, \mathrm{VI}$ ); legislar e combater a poluição (artigos 23,VI e 24,VI); registrar, acompanhar e fiscalizar à concessão de direito de pesquisa e de exploração de recursos hídricos em seus territórios (CF, artigo 23, XI).

Na Lei 12.608/12, Defesa Civil é definida no Brasil como: "[...] o conjunto de ações de prevenção ${ }^{3}$, mitigação ${ }^{4}$, preparação $^{5}$, resposta ${ }^{6}$ e recuperação ${ }^{7}$ destinadas à redução dos riscos de desastres com vistas à preservação do moral da população, o restabelecimento da normalidade social e a proteção civil". A partir destas ações são então definidas as responsabilidades de cada ente federativo dentro delas de forma a contemplar todo o ciclo.

\footnotetext{
${ }^{3}$ A prevenção (ou prevenção de desastres) expressa o conceito e a intenção de evitar por completo os possíveis impactos adversos (negativos) mediante diversas ações planejadas e realizada antecipadamente. (ESTRATÉGIA...,2009, p. 25, Apud Souza, 2016, p.24)

${ }^{4}$ Mitigação é a diminuição ou a limitação dos impactos adversos das ameaças e dos desastres afins. (ESTRATÉGIA..., 2009, p. 21 Apud Souza, 2016, p.24)

58 Preparação são conhecimentos e capacidades desenvolvidas pelos governos, profissionais, organizações de resposta e recuperação, comunidades e pessoas para prever, responder e se recuperar de forma efetiva dos impactos dos eventos ou das condições prováveis, iminentes ou atuais que se relacionam com uma ameaça. (ESTRATÉGIA..., 2009, p. 24 Apud Souza, 2016, p.25)

${ }^{6}$ Resposta é a prestação de serviços de emergência e de assistência pública durante ou imediatamente após a ocorrência de um desastre, com o propósito de salvar vidas, reduzir impactos sobre a saúde, garantir a segurança pública e satisfazer necessidades básicas de subsistência da população afetada. (UNISDR, 2009, p. 28 Apud Souza, 2016, p.25)

7 A restauração é o melhoramento, se necessário, das plantas, instalações, meios de sustento e das condições de vida das comunidades afetadas por desastres, incluindo esforços para reduzir os fatores de risco de desastres. (ESTRATÉGIA..., 2009, p. 26 Apud Souza, 2016, p.25)
} 

de forma sistêmica e aberta, com caráter multidisciplinar dos órgãos setoriais, harmonicamente nos três níveis de governo (federal, estadual e municipal)" o autor ainda destaca que tal legislação propicia a participação popular e dos governos locais nas ações de redução de riscos de desastres.

Podemos observar, ainda, que a questão econômica possui uma condição importante dentro da Política Nacional de Proteção e Defesa Civil como indicador para classificar situação de emergência ou estado de calamidade pública, como pode ser percebido nos artigos $4^{\circ}$ e $5^{\circ}$ da Instrução Normativa ํo. 1 de 24 de agosto de 2012, de acordo com o texto:

\begin{abstract}
Art. $4^{\circ}$ Caracteriza os desastres de nível I [situação de emergência] a ocorrência de pelo menos dois danos [...] que, no seu conjunto, importem prejuízos econômicos [...] públicos que ultrapassem $2,77 \%$ (dois vírgula setenta e sete por cento) da receita corrente líquida anual do Município, do Distrito Federal ou do Estado atingido [...] [Ou] Prejuízos econômicos privados que ultrapassem $8,33 \%$ (oito vírgula trinta e três por cento) da receita corrente líquida anual do Município, do Distrito Federal ou do Estado atingido. (BRASIL, 2012)

Art. 5o Caracteriza os desastres de nível II [estado de calamidade pública] a ocorrência de pelo menos dois danos [...] que, no seu conjunto importem prejuízos econômicos [...] públicos que ultrapassem $8,33 \%$ (oito vírgula trinta e três por cento) da receita corrente líquida anual do Município, do Distrito Federal ou do Estado atingido [...] [Ou] Prejuízos econômicos privados que ultrapassem $24,93 \%$ (vinte e quatro vírgula noventa e três por cento) da receita corrente líquida anual do Município, do Distrito Federal ou do Estado atingido. (BRASIL, 2012)
\end{abstract}

Se continuarmos analisando a Lei 12.608/12, perceberemos que 0 sistema é constituído pelos órgãos e entidades da administração pública federal, estadual, pelo Distrito Federal e Municípios, além das entidades públicas e privadas de atuação significativa na área de proteção e defesa civil, tendo sua articulação centralizada na Secretaria Nacional de Proteção e Defesa Civil, pertencente ao Ministério da Integração Nacional.

Já no artigo 10 da referida Lei, temos a constituição do SINPDEC que é composto pelos órgãos e entidades da administração pública federal, dos Estados, do Distrito Federal e dos Municípios e pelas entidades públicas e privadas de atuação significativa na área de proteção e defesa civil. Além do 
seu parágrafo único que define sua finalidade, qual seja contribuir no processo de planejamento, articulação, coordenação e execução dos programas, projetos e ações de proteção e defesa civil.

Dessa maneira, portanto, podemos ter um panorama da estruturação de como surgiu e de que maneira está estabelecia a Proteção e Defesa Civil em nosso país, com uma legislação que, embora possua oportunidades de melhorias, trouxe grandes avanços definindo de forma clara as atribuições de cada um dos níveis da federação, muito embora observemos uma grande defasagem em relação à operacionalização do que é preconizado na Lei.

\section{DESAFIOS DA DEFESA CIVIL MUNICIPAL}

Como dito anteriormente, sobre o município recai a responsabilidade de executar a maior parte das ações de Proteção e Defesa Civil, cabendo aos Estados e à União atividades complementares e suplementares quando a municipalidade não tiver as condições para atender a todas as demandas. Dessa maneira, normalmente se faz necessária uma estrutura com recursos diversos, adequadas às suas necessidades.

Refletindo sobre as ações de prevenção, mitigação, preparação, resposta e recuperação, podemos pensar no quão diversificados devem ser os recursos humanos e materiais disponíveis. Por exemplo, enquanto no período de normalidade, ao oferecermos uma capacitação para a população onde 0 ensino teórico seja o aspecto mais importante, podemos utilizar profissionais, eventualmente, que não tenham o aspecto de condicionamento físico como principal qualidade, em uma atividade realizada dentro de uma ação de resposta em condições extremas, não podemos prescindir de um condicionamento físico adequado.

Em outra frente, um município que possua em seu território áreas de difícil acesso e não possua dentre suas viaturas aquelas que possibilitem a chegada dos agentes de defesa civil, quando necessário, naquelas regiões, 
não importa quantos veículos haja, os mesmos não irão atender a todas as necessidades, no tocante à Defesa Civil, daquele município.

Conseguiríamos elencar aqui uma série de outros aspectos que poderiam ser analisados quanto à sua adequação, como a escala de serviço adotada, número e características de voluntários, maneira como realizam os procedimentos burocráticos, enfim, a ideia até este momento não é, de forma alguma, exaurir uma lista de atributos, mas de demonstrar que há muitos fatores envolvidos para que uma Defesa Civil Municipal possa desempenhar de forma adequada a missão que the é confiada e isso tudo sem esquecermos o protagonismo do município na primeira resposta quanto às ações a ele atribuídas nesta área.

Segundo (LUGON; PALASSI, 2012, p. 347) "a maioria dos desastres naturais pode ter seus efeitos minimizados ou agravados pela intervenção humana, cabendo à municipalidade, dentre outros atores, esforçar-se para prevenir e dar resposta a esses desastres, recuperando as comunidades atingidas". Isso demonstra o quanto é importante que o ente municipal conte com uma estrutura forte e adequada de proteção e defesa civil.

Como vimos até aqui o município tem um papel fundamental dentro do Sistema Nacional de Proteção e Defesa Civil (SINPDEC), porém, conforme dito por Souza (2016, p.135) eles são,

\begin{abstract}
"em sua maior parte, incapazes de resolução dos problemas locais relativos a desastres, se devendo isso a diversos fatores subjacentes, sendo um dos principais, a falta de aplicação de políticas públicas adequadas à redução de riscos de desastres e a grande interferência dos costumes políticos por vezes nefastos à sociedade".
\end{abstract}

A afirmação do autor está intimamente ligada aos aspectos ligados à cultura política vigente no Brasil, onde por muitas vezes verificamos o loteamento de estruturas públicas para atender aos interesses que, por muitas vezes, são completamente alheios à vontade e às necessidades da população.

Ainda neste aspecto, temos a questão do ciclo político-eleitoral que costuma promover mudanças em diversos órgãos, e não é diferente na Defesa Civil municipal, processo que ocorre comumente após serem eleitos os novos prefeitos e, por vezes, até mesmo durante o mandato por questões 
iminentemente políticas, perdendo muitas vezes a base técnica e a continuidade das atividades desenvolvidas.

De acordo com Queiroz e Bodstein (2011, p.17):

A atual Política Nacional de Defesa Civil (PNDC), não obstante os avanços por ela consignados, não logrou instrumentalizar uma visão integrada do objeto e das práticas da Defesa Civil, criando uma estrutura piramidal cuja base é extremamente frágil. Em todos os níveis de atuação e principalmente na base desta pirâmide, há necessidade de um maior nível de capacitação técnico-profissional dos atores bem envolvidos, o que não poderá ser feito sem a criação de uma carreira estruturada e bem definida em seus objetivos políticos e sociais.

E a questão aqui é exatamente essa, como poderíamos criar uma forma de fazer com que essas composições fossem mais técnicas? Como desenvolver um mecanismo que nos permita acompanhar de forma técnica os investimentos? Enfim, como saber se aquela Defesa Civil municipal está tendendo a desenvolver suas atividades voltadas para a Redução de Riscos de Desastres ou se está servindo apenas para acomodar apoiadores políticos? Aí repousa a necessidade da definição de parâmetros técnicos, desenvolvidos de forma científica e voltadas às ações de Proteção e defesa Civil.

\section{INDICADORES SOCIAIS}

A cada dia nossa sociedade evolui do ponto de vista da cidadania e da cobrança aos agentes públicos, a cada programa desenvolvido, a cada obra realizada; a todo momento existe uma busca de muitos setores sociais que estão atentos para constatarem que tudo ocorreu dentro da razoabilidade e legalidade, mas para que isso ocorra é necessário que haja uma forma de mensurar, de comparar e, para isso, na maior parte das vezes, são utilizados indicadores e para o caso das políticas públicas voltadas à população, são utilizados os indicadores sociais.

A fim de conceituarmos indicador social, iremos recorrer a Januzzi (2006, p.15) que define da seguinte forma:

Um indicador social é uma medida em geral quantitativa dotada de significado social substantivo, usado para substituir, quantificar ou operacionalizar um conceito social abstrato, de interesse teórico (para 
pesquisa acadêmica) ou pragmático (para a formulação de políticas). É um recurso metodológico, empiricamente referido, que informa algo sobre um aspecto da realidade social ou sobre mudanças que estão se processando na mesma.

Ainda segundo o autor, embora possamos observar algumas contribuições importantes para a construção de um marco conceitual sobre Indicadores Sociais nas décadas de 1920 e 1930, é apenas nos anos 60 que podemos observar o desenvolvimento científico desta área que buscava organizar um sistema abrangente de acompanhamento das transformações sociais e aferição do impacto das políticas públicas desenvolvidas.

Buscava-se, naquele momento, alguma medida que viesse a apresentar uma maior eficiência e fidedignidade com relação a retratar a realidade de uma sociedade, já que até então utilizava-se o PIB per capita, sem sucesso, como o padrão da mensuração do nível de desenvolvimento social já que em muitos países, especialmente nos subdesenvolvidos, as desigualdades sociais se agravavam, a despeito do crescimento deste indicador.

Diante dessa demanda, observamos a criação do Índice de Desenvolvimento Humano (IDH) que teve o objetivo de oferecer uma alternativa ao PIB per capita, já que este considera apenas a dimensão do desenvolvimento econômico. O IDH passou então a oferecer a medida do progresso de uma nação a partir de três dimensões: renda, saúde e educação, dessa maneira o mesmo oferece, por um lado uma forma de sintetizar a compreensão do tema, e por outro a ampliação e o fomento ao debate, já que desde a sua criação o índice vem recebendo adaptações metodológicas.

O Índice de Desenvolvimento Humano foi publicado pela primeira vez no ano de 1990 e foi criado por Mahbub ul Haq que contou com a colaboração do economista indiano Amartya Sen, ganhador do Prêmio Nobel de Economia de 1998, com o objetivo de tornar o índice uma medida geral e sintética do desenvolvimento humano, sendo calculado anualmente. 
O IDH possui variações, com ajustes metodológicos que visam a adequação a outras demandas, como é o caso do IDH-M que, conforme nos diz Wesendonck et al. (2015, p.1):

é composto por mais de 180 indicadores socioeconômicos, que dão suporte à sua análise e ampliam a compreensão dos fenômenos e dinâmicas voltados ao desenvolvimento municipal. Os procedimentos metodológicos empregados na composição do índice possibilitam determinar se uma melhora ocorrida em um município decorre da adoção de políticas específicas ou se o resultado obtido é apenas reflexo da queda dos demais municípios.

O IDH-M brasileiro, conforme indicado no Atlas Brasil, "considera as mesmas três dimensões do IDH Global - longevidade, educação e renda, mas vai além: adequa a metodologia global ao contexto brasileiro e à disponibilidade de indicadores nacionais". Dessa maneira, e tendo indicadores mais adequados para este tipo de mensuração, esse índice oferece a oportunidade de registrar a história dos municípios do país sob outra perspectiva.

A grande questão é que para que haja subsídios para acompanhamento de políticas públicas, um direcionamento adequado de investimentos e, enfim, para que se possa saber a efetividade do que é realizado é preciso que haja uma medição de resultados e, para isso, os indicadores sociais têm se mostrado valorosos aliados nesse processo, sendo imprescindíveis nesse contexto.

\section{CRIAÇÃO DO IPDC}

Para começar a abordagem desta parte de nosso estudo, de acordo com Deming (1989), não é possível gerenciar o que não se mede e não há como ter sucesso em algo que não se gerencia, pelo fato de não haver a possibilidade de um acompanhamento efetivo. Dentro desta ideia, fica claro que sem uma forma de aferir, torna-se inviável qualquer tipo de acompanhamento ou otimização, seja qual for o processo. 
Soma-se a tal pensamento a questão do quanto é importante para a população de um município ter a sua Defesa Civil local bem estruturada, pronta para executar as ações afetas a si de forma adequada às demandas, prevenindo a ocorrência de desastres, mitigando seus efeitos ou sua potencialidade, preparando os diversos atores para possíveis ocorrências, respondendo de forma eficiente e rápida para o que for demandada e recuperando áreas atingidas da melhor e mais breve maneira.

Algo fundamental para que essa realidade aconteça é realizar uma boa gestão, de maneira geral, desse órgão e, para isso, torna-se fundamental a formulação de um indicador social adequado, pois segundo Januzzi (2006, p.15), "o indicador social é um instrumento operacional para monitoramento da realidade social, para fins de formulação e reformulação de políticas públicas".

Nesse sentido fica clara a necessidade de que seja criado o Índice de Proteção e Defesa Civil (IPDC), levando em conta as diversas variáveis relacionadas a esta complexa atividade, desde recursos humanos, recursos materiais, viaturas, comunicação e equipamentos, até as próprias propensões peculiares ao município em questão.

O IPDC poderá, em sua criação, utilizar como modelo para sua metodologia o Índice de Desenvolvimento Humano, guardando, logicamente, as variáveis relativas às diferentes ações de defesa civil e outras que possuam influência sobre a atividade, ponderando essa influência de maneira a atribuir um peso compatível com sua importância no processo.

Com essa metodologia e a consequente atribuição de valores aos índices de cada um dos municípios, será possível compará-los e hierarquizálos, mesmo que suas realidades, relacionadas aos fatores preponderantes de redução dos riscos de desastres, sejam completamente diferentes entre si, algo que é impossível de ser feito hoje com as ferramentas disponíveis.

Pode-se ainda, para a construção do IPDC, utilizar o modelo adotado no Índice de Desempenho do Sistema Único de Saúde (IDSUS) que visa 
estabelecer parâmetros para direcionar os investimentos, bem como aferir qualidade e efetividade dos serviços desenvolvidos pelo SUS. Este índice "também busca avaliar o desempenho do SUS em relação aos seus princípios e diretrizes: regionalização, hierarquização, descentralização com comando único, responsabilidade tripartite" (OLIVEIRA; PASSADOR, 2014, p. 2395). Desta maneira, à semelhança do SUS, seria possível, por exemplo, a definição de estruturas mínimas de órgãos municipais de proteção e defesa civil.

E finalmente, com essa hierarquização, haverá indubitavelmente um estímulo para que o componente político e o componente técnico, ambos fundamentais para o funcionamento das boas práticas ligadas à democracia e à eficiência, possam dialogar de forma mais estreita e equilibrada, a fim de que se desenvolva um trabalho adequado em suas Defesas Civis municipais. Assim, teremos uma nova componente nesse sistema de forças locais, causando instabilidade e concorrendo para a busca de novas configurações para que se atinja o equilíbrio.

Cabe ainda recomendar que em sua construção o IPDC atenda aos atributos preconizados por Januzzi (2006) como: relevância social ${ }^{8}$, validade ${ }^{9}$, confiabilidade $^{10}$, cobertura $^{11}$, sensibilidade ${ }^{12}$, especificidade ${ }^{13}$, inteligibilidade ${ }^{14}$, periodicidade $^{15}$, factibilidade ${ }^{16}$ e historicidade ${ }^{17}$. Dessa maneira, o indicador

\footnotetext{
${ }^{8}$ Relevância social da temática à qual o indicador se refere é, com certeza, um atributo fundamental para justificar sua produção e legitimar seu emprego no processo de análise, formulação e implementação de políticas.

${ }^{9}$ A validade de um indicador corresponde ao grau de proximidade entre o conceito e a medida, isto é, a sua capacidade de refletir, de fato, o conceito abstrato a que o indicador se propõe a "substituir" ou "operacionalizar".

${ }^{10}$ A confiabilidade de um indicador é uma propriedade relacionada à qualidade do levantamento dos dados usados no seu cômputo [...] um indicador confiável sempre exibirá a mesma cifra se a dimensão da realidade empírica a que ele se refere permaneceu estática.

${ }^{11}$ Idealmente, procura-se empregar sempre indicadores de boa cobertura espacial ou populacional, que sejam representativos da realidade empírica em análise.

${ }^{12}$ A sensibilidade de um indicador diz respeito a sua capacidade em refletir mudanças significativas se as condições que afetam a dimensão social referida se alteram.

${ }^{13}$ Especificidade do indicador corresponde a sua propriedade em refletir alterações estritamente ligadas às mudanças relacionadas à dimensão social de interesse.

${ }^{14} \mathrm{~A}$ inteligibilidade diz respeito à transparência da metodologia de construção do indicador.

${ }^{15}$ Para que se possa acompanhar a mudança social, avaliar o efeito de programas sociais implementados, corrigir eventuais distorções de implementação é necessário que se disponha de indicadores levantados com certa regularidade.
} 
terá uma fundamentação técnica adequada e embasamento científico para sua produção, implementação e manutenção.

Nesse sentido, levando-se em conta que a Lei 12.608/12 que evidencia em seu conteúdo as cinco ações voltadas à proteção e defesa civil, o IPDC deverá ser desenvolvido em duas dimensões, sendo a primeira com um espectro positivo de pontuação e focada nas ações de prevenção, mitigação e preparação - que são focadas na realidade do risco. A segunda dimensão terá um espectro potencialmente negativo e levará em conta a realidade do desastre, logo terá seu foco nas ações de resposta e recuperação. Esta dimensão, inicialmente terá "zero" como valor de partida, e contará negativamente na medida em que a atuação da defesa civil municipal se mostrar ineficiente nessa fase, indicando que seus serviços ainda carecem de adequação em relação às suas demandas.

\section{CONCLUSÃo}

Ao longo deste estudo, verificamos que é fundamental para a sociedade brasileira que as políticas para a redução de riscos de desastres sejam implementadas da forma mais eficiente possível e em todos os níveis da federação a fim de que seja garantida uma maior segurança aos cidadãos como um todo. Vimos, porém, que as ações relativas a esta atividade são numerosas, amplas e complexas e isso traz uma grande dificuldade na própria estruturação do Órgão de Defesa Civil.

Vale ressaltar ainda que a maior parte da execução destas ações, muitas delas elencadas na Lei $12.608 / 12$, recai sobre o município que tem a atribuição da primeira resposta, podendo contar com a ajuda do Estado e da

\footnotetext{
${ }^{16}$ A factibilidade de obtenção do indicador a custos módicos é um aspecto crucial na construção e seleção de indicadores sociais para uma dada temática.

${ }^{17} \mathrm{O}$ que se denominou de historicidade de um indicador é a propriedade de se dispor de séries históricas extensas e comparáveis do mesmo, de modo a poder cotejar o valor presente com situações do passado, inferir tendências e avaliar efeitos de eventuais políticas sociais implementadas.
} 
União de forma complementar. Isso faz com que a municipalidade tenha protagonismo em muitas dessas atividades.

Destacamos que os órgãos de proteção e defesa civil, especialmente os municipais, estão sujeitos a uma série de fatores, muitos deles de cunho político, que influenciam diretamente na estruturação, composição e, por conseguinte, no funcionamento do referido Órgão e que não há atualmente uma ferramenta que nos possibilite avaliar de forma ampla, de apontar uma DCM como adequada ou, ainda, não há uma forma de comparar esses Órgãos.

E é exatamente neste sentido que se faz necessário a criação de um Índice de Proteção e Defesa Civil de maneira que tenhamos a possibilidade de mensurar a adequação da DCM, podendo comparar diferentes Órgãos desta natureza, hierarquizar, e até mesmo orientar a estrutura adequada para uma determinada Defesa Civil municipal, já que os indicadores que comporão o IPDC serão de conhecimento de todos e, com isso, o Prefeito poderá ter uma referência para investimento que deverá fazer neste Órgão.

Por fim, a criação do IPDC irá possibilitar uma maior transparência com relação à eficiência das defesas civis municipais de maneira que, a exemplo do que ocorre com o IDH, haja uma exposição desses Órgãos para a sociedade como um todo, criando uma eventual pressão popular e, até mesmo governamental em nível de Estados e União, no sentido de cobrar melhorias e investimentos, quando necessário, para que sua DCM conte com uma avaliação positiva, refletindo assim, na tendência pela busca de um processo de melhoria contínuo, tendo como maior beneficiária a população brasileira.

\section{REFERÊNCIAS}

ATLAS DE DESENVOLVIMENTO HUMANO. Banco de dados IDH-M. Disponível em: <http://www.atlasbrasil.org.br/2013/pt/o_atlas/idhm/>. Acesso em: 24.11.2018. 
BARRERA, A. A.; SOUZA, A. S.; MARTINS, P. L. A evolução do direito resiliente no Brasil. In: Congresso Estadual de Prevenção dos Efeitos da Estiagem Norte e Noroeste - RJ, 1, 2018, Campos dos Goytacazes. Anais. P.1 $-23$.

BRASIL; Constituição da República Federativa do Brasil. Brasília, Senado Federal, Brasília: 1988

BRASIL. MINISTÉRIO DO DESENVOLVIMENTO REGIONAL. Marco de Sendai. Disponível em: https://www.mdr.gov.br/images/stories/ArquivosDefesaCivil/ArquivosPDF/Send ai_Framework_for_Disaster_Risk_Reduction_2015-2030-Portugus.pdf. Acesso: 12.05.2019.

DEMING, W. E. O método Deming de Administração. 5. Ed. São Paulo: Marques Saraiva, 1989.

DEPARTAMENTO DE PREVENÇÃO E PREPARAÇÃO. Módulo de formação: noções básicas em proteção e defesa civil e em gestão de riscos: livro base / Ministério da Integração Nacional, Secretaria Nacional de Proteção e Defesa Civil, Departamento de Minimização de Desastres. - Brasília: Ministério da Integração Nacional, 2017, p.98.

EIRD. Terminología sobre reducción del riesgo de desastres. ONU. Genebra: 2009.

JANUZZI, P. M. Indicadores sociais no Brasil: conceitos, fontes de dados e aplicações. 3. Ed. São Paulo: Alínea, 2006.

BRASIL. Lei Federal no 12.608, de 10 de abril de 2012. Institui a Política Nacional de Proteção Defesa Civil - PNPDEC; dispõe sobre o Sistema Nacional de Proteção e Defesa Civil - SINPDEC e o Conselho Nacional de Proteção e Defesa Civil - CONPDEC; autoriza a criação de sistema de informações e monitoramento de desastres; altera as Leis nos 12.340, de 10 de dezembro de 2010, 10.257, de 10 de julho de 2001,6.766, de 19 de dezembro de 1979, 8.239, de 4 de outubro de 1991, e 9.394, de 20 de dezembro de 1996; e dá outras providências. Diário Oficial [da] União. Brasília, DF, 2012. Disponível

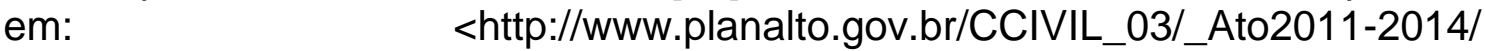
2012/Lei/L12608.htm>. Acesso em: 25.11.2018.

EBC. AGÊNCIA BRASIL. Conferência com 195 países em Paris tenta chegar a novo acordo climático. Publicação de novembro de 2015. Disponível em: <https://agenciabrasil.ebc.com.br/internacional/noticia/201511/paises-se-reunem-em-paris-para-tentar-chegar-novo-acordo-climatico>. Acesso: 13.07.2020. 
Revista Científica do Corpo de Bombeiros Militar de Pernambuco

Artigo Publicado no Vol.07 N.19 - Julho a Dezembro 2021 - ISSN 2359-4829

Versão on-line disponível em: $\underline{\text { http://www.revistaflammae.com }}$

LUGON, A. P.; PALASSI, M. P. Participação dos Núcleos de Defesa Civil do Município de Vitória na Gestão de Desastres Naturais. Santa Catarina: Psicologia Política, 12(24), 345-361, 2012.

OLIVEIRA, L. R.; PASSADOR, C. S. Saúde Pública no Brasil: a utilização do índice de desempenho do SUS na avaliação da alocação dos recursos dos municípios. Revista Eletrônica Gestão \& Saúde, V. 5, n. 4, p.2387-05, 2014.

ORGANIZAÇÃO DAS NAÇÕES UNIDAS. Nova Agenda Urbana. 2016. Disponível em:<http://habitat3.org/wp-content/uploads/NUA-PortugueseBrazil.pdf?fbclid=IwAR2kolM7MtgBh6i57G4fxWeWpbK52Jr7sXIrGdBbJF81bF2 GSzY527FWdAY>. Acesso: 17.07.2020.

QUEIROZ, E.; BODSTEIN, A. Território e bacias hidrográficas: reflexões a propósito da gestão de recursos hídricos e seus possíveis desdobramentos sobre as práticas de Defesa Civil frente aos desastres de origem hídrica. Revista Científica Internacional, v. 1, n. 16, jan./mar. 2011.

SANTOS, A. E.; ROCHA, I. O. Em busca de uma gênese para a defesa civil no Brasil. Revista Brasileira de Planejamento e Desenvolvimento, v. 7, n. 1, p. 128-144, jan./abr. 2018.

SOUZA, A. S. A gestão de riscos e desastres por colapso no Sistema Guandu, afetando 0 abastecimento de água potável na região metropolitana do Rio de Janeiro. 2019. Dissertação (Mestrado em Defesa e Proteção Civil) - Instituto de Geociências, Universidade Federal Fluminense, Rio de Janeiro.

UNIVERSIDADE FEDERAL DE SANTA CATARINA. CENTRO UNIVERSITÁRIO DE ESTUDOS E PESQUISAS SOBRE DESASTRES. Atlas brasileiro de desastres naturais: 1991 a 2012 / Centro Universitário de Estudos e Pesquisas sobre Desastres. 2. Ed. r. ampl. - Florianópolis: CEPED UFSC, 2013.

WESENDONCK, C. C. et al. Análise do IDH-M (1991 A 2010) do Conselho Regional de Desenvolvimento do Médio Alto Uruguai. VII Fórum sobre desenvolvimento regional. Universidade de Santa Cruz do Sul. Rio Grande do Sul, 2015. 